DOI: $10.20472 / E F C .2018 .009 .010$

\author{
LONTUM NCHADZE \\ Cameroon Ministry of Finance, Cameroon
}

\title{
SCOPE ECONOMIES IN CAMEROON'S TELECOMMUNICATIONS SECTOR.
}

\begin{abstract}
:
This study examines whether the simultaneous provision of multiple services leads to a reduction in the operating costs for concession holding firms in Cameroon's telecommunications industry. With the use of financial accounting information and output statistics from 2005 to 2012, I estimate a Seemingly Unrelated Regression Equation (SURE) model for 4 linear cost functions. The use of SURE permits us to account for cross-equation contemporaneous correlation which may arise due to correlated shocks to technological changes in the industry or from spillovers from industry wide or economy wide shocks. The results establish that simultaneous provision of domestic and international calls, and of telephone and internet lines are all cost increasing, while enhancing the use of existing network capacity is cost reducing. Hence, I recommend that when firms choose to enhance the capacity utilisation of their existing infrastructure by adding to their service mix, authorities should always check the cost implications in order to avoid predatory behaviour. Instituting separate accounting procedures for defined categories of services could greatly aid this effort.
\end{abstract}

\section{Keywords:}

Scope Economies, Concession Holding Firm, Sub-Additivity, Seemingly Unrelated Regression.

JEL Classification: D22, D43, L25 


\section{Introduction}

The knowledge of costs is crucial in any industry, and has proven to be of special importance in telecommunications (Fuss and Waverman, 2002). Knowledge of cost does not only assist the firm internally in the allocation of resources, but also influences decision making among external stake holders such as policy makers in the process of regulation.

However, a determination of costs in the telecommunication sector, especially at an individual service level, is inherently difficult. Cave et al (2002) identify three reasons for this: Firstly, the telecommunications carrier provides multiple services over a certain geographic area using capital that is fixed and common across a variety of applications. In addition, the impact of technological advance is also unevenly spread over the range of assets and services. Finally, since the carriers and the regulators have varying objectives, the information publicly available on cost has always been limited. Consequently, the firm has had the knowledge of its costs, yet the state and the regulator have needed to regulate prices and to determine where entry, if any, should be allowed

The task of resolving this information asymmetry around the nature of cost in the telecom sector has naturally been assumed by economists, and an important part of the debate has centered around the nature of the cost function. Since the early part of the $20^{\text {th }}$ century, the telephone industry around the world has largely been organised as a natural monopoly under the assumption that its cost structure is subadditive (Block et al, 2001). When a firm's cost function is subadditive (for given input prices) it can produce an arbitrary output vector more cheaply than any two firms faced with the same cost function (Baumol and Braunstein, 1977).

In the literature, this phenomenon is referred to as Economies of scope. First suggested by Panzar and Willig (1975) and outlined in Panzar and Willig (1981), economies of scope are said to exist when it is cheaper for one firm to simultaneously produce multiple products than multiple firms each producing a single of the same products. Conceptually, economies of scope arise from two main sources; spreading of fixed costs over an expanded product mix, and from the cost complementarities that can arise between different output categories if functional activities are carried out under the umbrella of one firm (Pulley and Humphrey, 1993).

Since its inception, Economies of scope have been the main tool for empirical investigation of the cost structure of the telecommunication industry, with significant policy implications. A major example was the January 1984 divestiture of American Telecom and Telegraph (AT\&T)'s 22 Bell operating companies to 7 regional holding 
companies. This happened because Evans and Heckman (1984) had found no economies of scope within the long-distance and toll-call operations of the erstwhile combined AT\&T organization, thus arguing for the break-up of the toll-call and local exchange components of AT\&T's business. ${ }^{1}$

The existing theoretical literature does not point to a precise mechanism of scope economies in the telecommunications industry. Empirical findings that support a scope economies outcome in the industry propose factors such as very high rate of technological change, excess network capacity, Network or club externalities, and a high potential for cross subsidization in the use of telecommunications equipment. Falch (1997) identifies Three different types of scope economies in the telecommunications sector: Economies of horizontal integration (telephony and data); Economies of vertical integration within the network (local and long distance, voice and value added network services); and Economies of vertical integration beyond the network (information production and distribution).

However, as this paper shows, the distribution of costs across services is affected by technological change in a much more dynamic way. With digitalization, the nature of access line diversity reduces to a much more limited line typology as the boundaries between say business, residential and public lines become technically irrelevant. Wireless services alone are +delivered by different providers deploying different technologies such as Wi-Max, Wi-Fi, EVDO, GPRS, and CDMA. Also, increased access to the internet and the proliferation of VOIP and free video chat services have largely rendered mute the need for international calls through the telephone exchange.

This paper also shows that the provision of additional services does not always happen without bringing in significant service specific costs. Termination charges that domestic firms pay to foreign providers may force domestic firms to leverage funds from other services in order to maintain their market share in the international calls market, or to ensure subscribers do not switch to other providers with a more affordable call mix. International calls require different types of equipment such as trunk switches. Consequently, the scope economy impact on costs can be vitiated since additional plant-specific capabilities have to be created within the firm. These capabilities may not always be easily leveraged across the rest of the firm. At times, terminal equipment for certain services are provided for free or with access charges that do not cover the purchase price. If the burden of such service specific costs exceed the advantages that arise from the spreading of fixed costs and/or the cost complementarities that arise

\footnotetext{
${ }^{1}$ Subsequently, Charnes et al. (1988), using the same data-set as Evans and Heckman (1984), found the existence of economies of scope between the local and toll-call operations of AT\&T, arguing, therefore, that the break-up of AT\&T was a mistake.
} 
from separate functional activities, the firm cannot enjoy scope economies.

Telecommunications play an increasingly important role in the world economy. According to the Telecommunications Industry Association (TIA), the global telecommunications industry was about $\$ 4.7$ trillion worth in 2012. The service revenue of the global telecommunications industry was estimated to be

$\$ 1.5$ trillion in 2010 , corresponding to $2.4 \%$ of the world's gross domestic product (GDP). Despite this, few economists in the rather equivocal scope economies literature have focused their analysis on the telecommunications sector, especially given that the industry is very amenable to service diversification. Granted, Banker et al (1998) examined whether the existence of scope economies leads to reductions in unit costs for a sample of the key firms making up the local exchange sector of the United States Telecommunications Industry. Data for the years 1988 to 1992 were examined and the results established that the generation of multiple outputs, using the resources and infrastructure that the firms possess, does lead to reduction in average unit costs for the firms studied. Bloch et al (2001) employed a composite cost function to examine the cost structure of Australian telephone services. The composite cost model combines the log-quadratic input price structure of the translog model with a quadratic structure for multiple outputs. Model estimates on Telstra system data from 1926 to 1991 revealed that the production of Australian telephone services exhibits economies of scope.

To investigate the presence of scope economies among concession holding firms in Cameroon's telecommunications sector, I obtain data on four cost categories from financial accounting information submitted to the telecommunications regulatory board by the firms concerned. I also use output statistics for two output categories at two levels each. These statistics are published in the annual reports of the telecommunications market observatory in the ministry of post and telecommunications. Three firms are considered: CAMTEL; MTN Cameroon; and Orange $\mathrm{CM}^{2}$

As discussed later, this study makes efforts to deal with methodological flaws inherent in empirical analysis involving scope economies. I do this by accounting for crossequation contemporaneous correlation which may arise due to correlated shocks to technological changes in the industry or from spill overs from industry wide or economy wide shocks. The rest of the discussion proceeds as follows: The next section discusses how the competition and regulatory environment for telecommunications services in Cameroon has changed over the last two decades. Section III describes the

${ }^{2}$ A fourth firm commenced operation in September 2014 under the brand name "Nexttel" but could not be considered for this study since its operations lie outside the study period. 
data and methodology. Section IV describes the results and section $\mathrm{V}$ offers concluding remarks.

\section{Contextual History and Current trends in Cameroon's Telecommunications Sector.}

Before 1990, as in most African countries, telecommunication services (like other public utilities) were managed under tight state control. The public enterprise INTELCAM (International Telecommunications Corporation of Cameroon)was in charge of operating and developing international telecommunication installations, while the Ministry of Post and Telecommunications (MINPOSTEL) set the rules, ensured they were applied and was itself an operator, given that it also developed and provided domestic telecommunications services. The results did not always live up to expectations. The coverage rate and quality of service offered remained largely inadequate.

Following the economic crisis of the mid 1980s that saw a sudden and rapid recession of the Cameroonian economy, the government adopted a structural adjustment program under the direction of the World Bank. This program was meant to address key macroeconomic and sectorial issues facing the country over the medium term. According to the World Bank's project document for this program, two of its basic elements were the deregulation of internal commerce with a view towards lowering the domestic cost structure, and the restructuring and rehabilitation of the public enterprise and banking sectors (World Bank, 1989).

In this light, the government, in June 1990 signed an order on the programmed privatization of public and semi-public enterprises. The privatization program was expected to bring important benefits in the form of increased investment in the rehabilitation of existing infrastructure, reduce costs, and improve the availability of services (IMF/Government of Cameroon, 1999).

The telecom sector became part of this privatization program in June 1995, when the authorities decided to thoroughly reform network industry sectors such as water, electricity and telecommunications with a view to create a favourable environment in which to develop their infrastructure and services and thus to satisfy increasingly exigent demand. The process took the form of liberalization, state withdrawal from sectors concerned and the establishment of a more competitive market structure, enabling Cameroon to remain in step with the rapid global developments in the telecommunication sector (ITU, 2000). 
The first concrete step in this direction was the promulgation of the telecommunications act in $1998 .^{3}$

Henceforth, the government of Cameroon began issuing a series of decisions meant to encourage entry into the telephone industry. Two public enterprises: CAMTEL (for fixed telephone services) and CAMTEL MOBILE (for mobile telephone services) were set up to take over the telecommunication activities of the Ministry of Post and Telecommunications and of the public enterprise INTELCAM. Immediately, the process of privatizing both companies got underway.

The privatization of CAMTEL MOBILE was completed with a South African firm (MTN International) in February 2000, which led to the establishment of MTN Cameroon. 70\% of its share capital is owned by MTN International, and 30\% by the Cameroonian company, Broadband Telecom (MTN Cameroon, 2017). Earlier on (In June 1999), another GSM license was granted to France Cable and Radio subsidiary "Societe Camerounaise de Mobiles" (SCM). Its Mobile network was later rebranded Orange CM following the merger of the orange group with most of the France Telecom Mobile businesses (BuddeComm, 2012). Fixed-line incumbent CAMTEL finally re-entered the mobile market in 2009 as the third player. Till date its privatization has never been completed.

The telecom sector in Cameroon witnessed remarkable progress over the first decade of competition as the volume, quality and variety of services expanded and access charges dropped. However, recent developments in the conduct of the major telecom operators present new challenges with implications for all actors including service providers, users, potential entrants, and particularly the regulator.

Mirroring a trend throughout developing markets, the average revenue per user (ARPU) in Cameroon's Telecommunications sector has fallen continuously as lower income groups gain access to services. Nonetheless, as lower income groups are being targeted, the declining Average Revenue per User is putting pressure on the network operators' profit margins. Price wars have broken out recently in the form of special tariff plans and bonus options which price discriminate largely in favour of low income users.

As a reaction to these developments, the major operators are taking advantage of extra capacity in the network infrastructure by moving to provide other telecom services

\footnotetext{
${ }^{3}$ In July 1998, law no. 98/014 governing telecommunications in Cameroon was promulgated. It established the Telecommunication Regulatory Board (TRB) and attributed sector responsibilities to a variety of players: the operation of telecommunication networks to operators, regulatory matters to the regulatory board, and the definition of sector policy and the enactment of market regulations to the Telecommunication Administration.
} 
where market penetration is still relatively low, hence, higher growth potential. Examples of such services include prepaid internet, multimedia services, hosting, value added services, caller exchange, and call forwarding. Mobile network operators have established themselves as Internet Service Providers (ISPs) and are playing an increasing role in the broadband sector, competing directly (and possibly unfairly) with fixed or wireless broadband services, a welcome new revenue stream in an environment of shrinking voice revenues.

However, without proper regulatory oversight, such actions may introduce inefficiencies in to the market. The provision of multiple services is at times done in ways that may be construed as an act of bundling, an action which many jurisdictions consider to represent exclusionary conduct. How therefore do we distinguish service variety that is done for the purpose of efficiency from that done for anticompetitive purposes? According to Banker et al (1998), efficiency is guaranteed in the provision of multiple services if average costs for the firm fall when additional services are offered (Economies of scope). If this is not the case, the market is better-off if the firms are divested of these services.

For practical purposes, this study cannot integrate the broad range of services enumerated above. I shall therefore focus on two dimensions of service diversification with direct implications to all stake holders: Call diversification (domestic and international calls), and line diversification (Telephone and internet lines). Operational definitions and computational procedures for these constructs will be provided in the proceeding section.

\section{Methodology.}

This study covers the activities of three concession holding telecommunication firms in Cameroon (MTN Cameroon, Orange CM, and CAMTEL) for the 8 year period from 2005 to $2012 .{ }^{4}$ Before 2005, the firms could be considered as being at the entry stage as they still grappled with licensing issues and the laying of infrastructure. Telecom penetration was still below $15 \%$ and internet services were mostly brought to end users through third party commercial agents and a grey market of satellite gateway operators.

The study ends in 2012 for two reasons. Firstly, the period after 2012 was characterized by preparations for a new entrant, and it is expected that in this condition,

\footnotetext{
${ }^{4}$ This Time frame allows for the accommodation of CAMTEL's Mobile service (CT phone) who only entered the market later. This timeframe is also realistic for considering the provision of bundled services as in the earlier days, all the holders would have concentrated in the provision of traditional services only (Call Telephony).
} 
firms may behave in ways different from the past and may hence introduce bias into our study. The second reason has to do with concerns over data availability as statistical databases take time to be updated.

Besides their status as concession holding companies, the combined scale and scope of their activities make them the most suitable candidates for the study of output diversification and its effects on cost. Data obtained from the 2011 Telecom market report suggest that the three companies together controlled $100 \%$ of all residential lines (fix telephony), $95 \%$ of all mobile lines, as well as $80 \%$ of all public lines. CAMTEL is the sole legalized internet access provider, and the three companies combined hold $60 \%$ of the internet service provision market. Also, they handle $70 \%$ of all international call traffic (excluding voice over IP).

3(i) Data and Variables.

The study makes use of secondary data obtained from records pertaining to the individual firms lodged at the Telecommunication regulatory board and the telecom market observatory. Two types of records are used to generate data for this study: Financial accounting information and plant statistics.

Financial accounting information used in this study includes data on different expenses grouped into four different cost categories which constitute the dependent variables. Each dependent variable captures the costs associated with the different activities that underlie the provision of telecommunications services. The level of each separate cost category can be influenced by the diversity of outputs within each of the telecommunications companies. They include:

Plant specific expenses ( plant expenses); The costs of plant specific operations are measured as the sum of network support, general support, central office switching, central office transmission, information origination and termination, and cable and wire facilities expenses that are incurred by the companies.

Network and access expenses (network expenses); the expenses include network operations, testing, and plant operation administration, engineering, and access expenses. They enable the network to be maintained and developed on continuing bases. These costs are not attributable to a specific plant, and are similar to indirect overhead costs.

Customer operations expenses (customer expenses); The expenses contained in this category include product management, sales, product advertising, call completion services, number services and customer services expenses. These costs are 
identifiable with enabling the customer to subscribe to the network, and to generate and complete calls.

Corporate expenses (corporate expenses); Corporate expenses include executive and planning, accounting and finance, external relations, human resources, information management, legal, procurement, research and development, and other general and administrative expenses.

Plant statistics used in this study includes: Number of fixed telephone lines, number of mobile lines, number of internet lines, Minutes of domestic calls and minutes of international calls. These are then used to construct variables that proxy for output diversity in the telecom sector. They include:

Line diversity; this refers to the varieties of service lines provided by concession holding firms in Cameroon. We consider two varieties: Telephone lines (for voice services); and internet lines (for data services); with some degree of interaction as permitted by technologies like GPRS. We use the construct "Scope lines" as the access line diversity index, calculated as the inverse of the Herfindahl Hershman Index (IHI) of a carrier's access line mix. A concession holding company's access line mix consists of (I) Mobile Telephone lines [ML]; (ii) Fixed telephone lines [FL] and (iii) Internet subscription lines [IL]. Therefore scope lines is given by the equation:

(1) Scopelines $=\frac{1}{\text { HHDines }}$

Where $\mathrm{HHI}$ lines is the Herfindahl index of the line mix defined as $\mathrm{HHI}$ lines $=(\mathrm{ML} / \mathrm{lines})^{2}$ $+(\text { FL/lines })^{2}$

$+(\mathrm{IL} / \text { lines })^{2}$ and lines $=\mathrm{ML}+\mathrm{FL}+\mathrm{IL}$.

Call diversity: This refers to the variety of call services offered by Telecommunication firms in Cameroon. Concession holding firms in Cameroon basically offer two types of calls, domestic calls and international calls. There are some essential differences between these two types of calls that may have economic implications. Examples include: differences in termination charges; differences in switching infrastructure; differences in customer base; and differences in providers as international calls are also provided by unlicensed satellite gateway operators and through online applications like Skype and Google voice. We use the construct "Scope calls" as the call diversity index, specified as the inverse of the Herfindahl index of an operator's call mix. A concession holding telecommunication firm's call mix consists of local calls (LC) and international calls (IC). Therefore Scope calls is given by the equation: 
(2) Scopecalls $=\frac{1}{\text { HHIcalla }}$

Where $\mathrm{HHI}$ calls $=(\mathrm{LC} / \text { calls })^{2}+(\mathrm{IC} / \text { calls })^{2}$, calls $=\mathrm{LC}+\mathrm{IC}$ and $\mathrm{LC}$ and $\mathrm{IC}$ represent the volumes of local and international calls respectively.

Capacity Utilisation: This refers to the extent to which the installed facilities are being put to use. This serves as an important control against the inefficiencies that may arise due to service diversification. For instance, if the existing infrastructure is already highly utilised in the provision of current services, firms cannot expand existing services, let alone provide new services through the given channels without compromising the quality of those services. A good example is the problem of connectivity that generally arises when calls are made during high peak hours or festive periods. The construct Capacity usage is used to proxy for capacity utilisation. It is measured as the ratio of the total phone calls to total number of lines. Therefore capacity usage is given by the equation:

(3) Capacityusage $=\frac{1 \mathrm{c}+\mathrm{jc}}{\mathrm{ml}+\mathrm{fl}}$

Where LC and IC represent volumes of local and international calls respectively, while $\mathrm{ML}$ and $\mathrm{FL}$ represent numbers of mobile and fix telephone lines respectively.

Additional data are obtained from private publications, the African Telecommunications Union (ATU), the International Telecommunications Union (ITU), and the Telecommunications Industry Association (TIA).

3(ii) Model Specification and Estimation Procedure.

I adopt an approach based on estimating a linear multivariate model (Banker and Johnston, 1993) to test the role of multiple outputs production in engendering economies of scope among the firms. The model has four equations for each of four distinct cost categories, rather than one equation for total costs, and each equation has an identical set of explanatory variables. Scaled separate cost categories are the dependent variables in each equation, as follows:

(4) Plant expenses =

$\mathrm{B}_{10}+\mathrm{B}_{11}$ scopeline $+\mathrm{B}_{12}$ scopecall $+\mathrm{B}_{13}$ capacity usage $+\mathrm{E}_{1 \mathrm{t}}(5)$

Network expenses $=B_{20}+B_{31}$ scopeline $+B_{22}$ scopecall $+B_{33}$ capacity usage $+E_{2 t}$ 
(6)

Customer expenses $=B_{30}+B_{31}$ scopeline $+B_{32}$ scopecall $+B_{33}$ capacity usage $+E_{3 t}$

(7) Corporate expenses $=\mathrm{B}_{40}+\mathrm{B}_{41}$ scopeline $+\mathrm{B}_{42}$ scopecall $+\mathrm{B}_{43}$ capacity usage $+\mathrm{E}_{4 \mathrm{t}}$

Where:

B10, B20,---,B40>0.

B11, B21,---,B41<0.

B12, B22, ---, B42<0.

B13, B23, ---, B43<0.

The dependent variables are four separate cost categories discussed in the previous sub section;

Scope Line and Scope Calls are the principal independent variables capturing the impact of firms conducting multiple activities;

Capacity Usage captures the impact of capacity utilisation; and $E$ is a random error term for each equation $\mathrm{i}(4,7)$ for each year $\mathrm{t}(2005, \ldots, 2012)$.

The system of equations is additive and separable with respect to the independent variables.

The four equations in our model above collectively constitute a seemingly unrelated regression equations (SURE) model. Proposed by Arnold Zellner (1962), this is a generalisation of a linear regression model that consists of several regression equations, each having its own dependent variable and potentially different sets of exogenous explanatory variables. It differs from a simultaneous equation model in that none of the dependent variables is an explanatory variable in another equation.

A key feature of this model is that the error terms are independent across time, but may have cross equation contemporaneous correlation. ${ }^{5}$

According to Moon and Perron (2006), there are two main motivations for the use of Sur. The first one is to gain efficiency in estimation by combining information on

\footnotetext{
${ }^{5}$ In our model, the correlation among the equation disturbances could come from several sources such as correlated shocks to technological changes in the industry, as well as spillovers from industry wide or economy wide shocks.
} 
different equations. The second motivation is to impose and/or test restrictions that involve parameters in different equations.

The model can be estimated equation-by-equation using standard ordinary least squares (OLS). Such estimates are consistent, however generally not as efficient as the Sur method, which amounts to feasible generalized least squares with a specific form of the variance-covariance matrix.

This is a two-step process where in the first step, OLS regression for the first equation in the model is run. The residuals from this equation are then used to generate a consistent estimate for the covariance matrix. In the second step, we run generalized list squares regression (GLS) using the estimated covariance matrix to obtain the parameters of the model.

This estimator is unbiased in small samples assuming the error terms have a symmetrical distribution. In large samples, it is consistent and asymptotically normal with limiting distribution.

\section{Results and Analysis.}

Total annual expenditure in the industry rose steadily from 71.11 Billion FCFA in 2005 to 97.8 Billion FCFA in 2012, with CAMTEL accounting for $58.1 \%$ of all these expenditures, while MTN and Orange accounted for $22.65 \%$ and $19.20 \%$ respectively. This huge discrepancy can partially be explained by the fact that CAMTEL as a parastatal maintains a significantly larger work force, and has the duty of managing the network infrastructure on behalf of the industry.

For the cost categories, corporate expenses were largely predominant, averagely accounting for $77.61 \%$ of total annual expenditure by the industry, while all the other expenses (Plant specific, network and Access, and Customer operations) accounted for the remaining $22.39 \%$.

Figure 1 is a table of three graphs that offers a visual account of how expenses by the firms compared with each other, and how the various cost categories compared with each other during the study period. The graphs have been drawn to scale and the variables are uniform. For each point on the horizontal axis (Year), the point on the vertical axis (Expenditure) in the middle graph is a direct summation of the corresponding points along each panel on the left graph. Likewise, the same intuition can be used to compare the cost categories as corresponding points along each plot on 
the right graph sum up to the equivalent point along the middle graph.

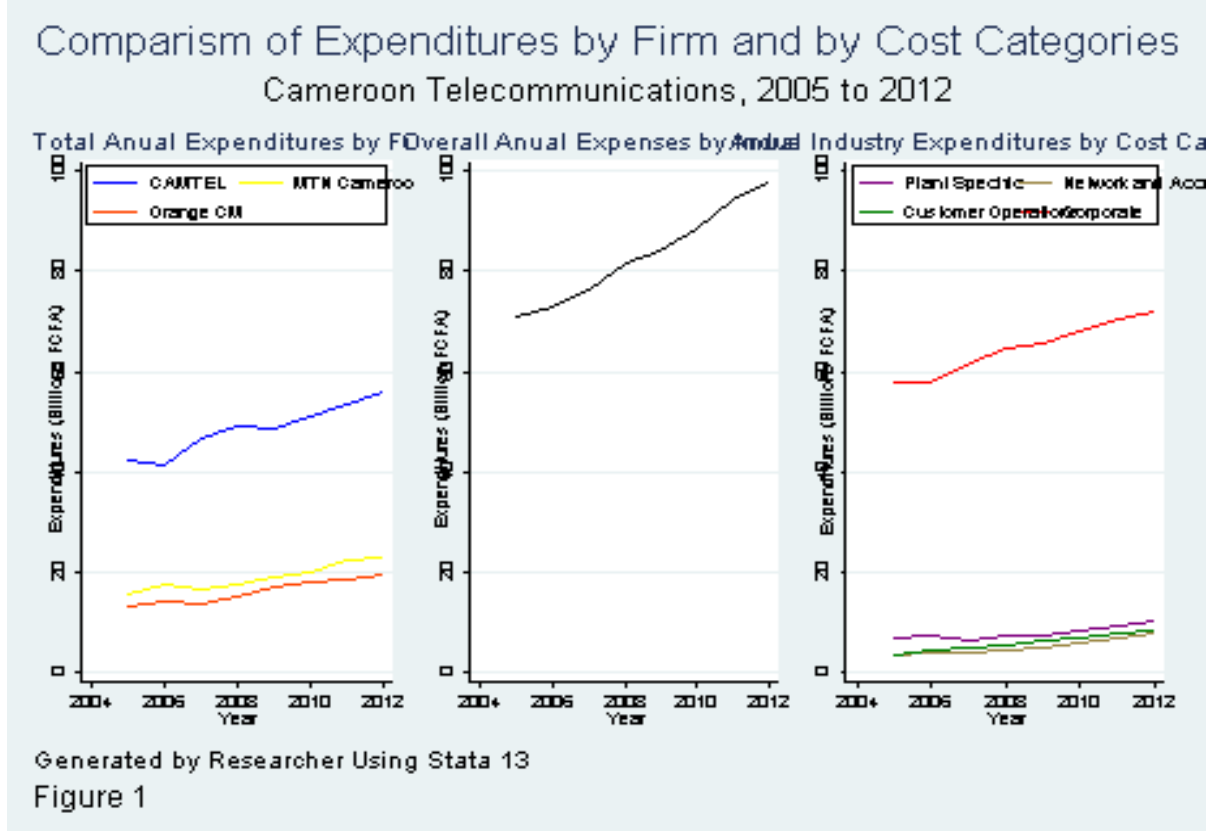

Now, turning to the output categories, we observed that MTN dominates its two rivals in both national and international calls. Orange and CAMTEL are respectively second and third. However, in the Lines category, while MTN still dominates its rivals in terms of telephone lines, CAMTEL dominates in the number of internet subscriptions, while Orange and MTN respectively follow. The details are contained in Table I.

Table I

Average annual output (2005 to 2012)

\begin{tabular}{|l|l|l|l|l|l|}
\hline $\begin{array}{l}\text { Output } \\
\text { Category }\end{array}$ & Level & \multicolumn{4}{|l|}{ Average Annual Output (2005-2012) } \\
\cline { 3 - 6 } & & CAMTEL & $\begin{array}{l}\text { MTN } \\
\text { Cameroon }\end{array}$ & Orange CM & Industry \\
\hline $\begin{array}{l}\text { Volume of } \\
\text { Calls (Millions }\end{array}$ & Local & 240.2648 & 1276.753 & 1163.063 & 2680.0809 \\
\cline { 2 - 6 } & International & 46.67163 & 76.7125 & 68.1125 & 191.49663 \\
\cline { 2 - 6 } $\begin{array}{l}\text { Minutes) } \\
\text { Number of } \\
\text { Lines } \\
\text { (Thousands) }\end{array}$ & Total & 286.9364 & 1353.466 & 1231.175 & 2871.5775 \\
\cline { 2 - 6 } & Internet & 67.807 & 23.824 & 28.4545 & 120.0855 \\
\hline
\end{tabular}

Source: Generated by Researcher Using Data from Multiple Sources 
Now, turning to the analysis of how output diversity influenced the operating costs of telecommunication firms in Cameroon, let us look at the results of the seemingly related regression equation (SURE) model represented by Equations 4 to 7 . These results are summarized in Table II.

Table II.

Regression results (coefficient estimates with * signifying significance at $5 \%$ level)

\begin{tabular}{|c|c|c|c|c|c|c|}
\hline \multirow[t]{2}{*}{ Equation } & \multicolumn{6}{|l|}{ Parameters } \\
\hline & Intercept & $\begin{array}{l}\text { Capacit } \\
y \\
\text { Utilisatio } \\
n\end{array}$ & Scope Calls & Scope Lines & R square & Chi square \\
\hline $\begin{array}{l}\text { Plant } \\
\text { Specific } \\
\text { Expenses }\end{array}$ & $-16.7101^{*}$ & $-3.28955^{\star}$ & $1.85052^{*}$ & $16.92185^{\star}$ & 0.9763 & $988.23^{*}$ \\
\hline \begin{tabular}{l} 
Network \\
\multicolumn{1}{c}{ an } \\
d Access \\
Expenses
\end{tabular} & $-13.92665^{\star}$ & $-3.384342^{*}$ & $1.603654^{*}$ & $13.99789^{*}$ & 0.9300 & $318.88^{*}$ \\
\hline $\begin{array}{l}\text { Custome } \\
\text { r } \\
\text { Operatio } \\
\text { ns } \\
\text { Expense } \\
\text { s }\end{array}$ & $3.276634^{*}$ & -.513975 & -1.124269 & 3972933 & 0.3331 & $11.99^{*}$ \\
\hline $\begin{array}{l}\text { Corpora } \\
\text { te } \\
\text { Expens } \\
\text { es } \\
\end{array}$ & $-69.93812^{*}$ & $-6.851383^{*}$ & -.6330115 & $85.85113^{*}$ & 0.9750 & 937.10 \\
\hline
\end{tabular}

Source: Generated by researcher on Stata 11 using data from multiple sources.

As can be observed, the percentages of the variations in operating cost accounted for by the explanatory variables range from $33 \%$ to $97.5 \%$ in all the four equations. The Chi square tests for goodness of fit are all significant.

However, the estimates do not generally turn out as hypothesized. The variables that capture scope economies (scope lines and scope calls) turn out as follows:

The coefficients of Scope lines are positive in all four equations, and significant in all but the customer operations equation. The implication is that the greater the diversity of access lines the higher the levels of operational costs for the firms. Banker et al (1998) 
suggests that with diversified access services provided to different customer groups in a given network, activities become fungible and costs levels can be reduced. However, the nature of access line diversity considered in Banker et al (1998) is very different from the one employed in this study. They use a line typology that includes Single business lines, multiple business lines, residential lines, public lines, mobile lines, and special access lines. With the introduction of the prepaid marketing option for telephone consumption, mobile lines dominated the landscape of telephone lines in Cameroon significantly. More so, fixed and mobile lines are already provided by separate entities and I adopt a line typology that would be common to all firms. I use this same logic in the consideration of internet lines. Different technologies like Wi-Max, Wi-Fi, EVDO, GPRS, and CDMA are currently deployed by different firms for the provision of wireless services alone.

Another factor that may be vitiating against the full enjoyment of scope economies by telecom firms lies in the way these lines are provided to consumers. Most of the terminal equipment like SIMs and modems, and at times telephones are acquired and provided exclusively by the operators, with an access charge that does not cover the purchase price and no rent included. In some cases, the equipment are sold with service bonuses valued far above the access charge, making some consumers to purchase these equipment, use up the bonuses and then abandon the equipment.

It is therefore important that authorities re-examine the conditions under which concession holding firms are permitted to compete in the data market. What we infer from these results is that concession firms make huge profits from the calls (voice) market, but then leverage these resources to offer services at a less profitable data (internet) market, where most operators are small scale localized entities. These market conditions may appear beneficial to end users in the short run, but hinder innovations and investments which are essential for the long term development of the market.

Also, I use the variable scope calls to capture the relative concentrations of domestic and international calls in the firms' call mix. Scope calls is negative in the last two equations as hypothesized but the coefficients are both insignificant, while they are significant and positive for the first two equations, implying that the provision of diverse types of calls is cost increasing for the firms.

This result is not very surprising. Technological complexity in the exchange may be vitiating against the full enjoyment of positive benefits that arise from activity sharing. International calls require different types of equipment such as trunk switches. Consequently, the scope economy impact on costs can be vitiated since additional plant-specific capabilities have to be created within the firm. These capabilities may not 
always be easily leveraged across the rest of the firm. In such situations, we will expect the provision of international calls to increase plant specific expenses as shown by these results.

In addition, increased access to the internet and the proliferation of VOIP and free video chat services like Messenger, Skype and Google hangout have largely rendered mute the need for international calls through the telephone exchange among internet users. This shift has largely biased the concentration of calls in favour of domestic calls.

Another factor that may lead to cost increases, particularly access expenses when international calls are provided is the need by domestic firms to pay termination charges to foreign companies. Although these costs can be shifted to consumers, the resulting high prices are demand and hence revenue reducing.

Two studies that agree with these findings are Shin and Ying (1992) and Leggette (1994). Both studies used the translog function to estimate the local exchange carriers cost function with data constructed from the Federal Communication Commission's Statistics of Communication Common Carriers. Shin and Ying (1992) concluded that the cost function is definitely not sub additive, and therefore efficiency gains could be achieved if the local exchange carriers were broken up. Leggette (1994) concluded that there were no economies of scope between his two outputs, private branch exchange and main station telephones.

The only variable to turn out as hypothesized is Capacity utilization which is negative for all four equations and significant in all but the Customer operations equation. This indicates that average operating costs are lowered with higher capacity utilization, supporting expectations.

This evidence is also consistent with previous telecommunications cost studies (Waverman, 1989), and sheds light on the importance of fully utilizing the fixed infrastructure in place to recover all associated costs. Local telephone companies are localized monopolies primarily because it is wasteful to duplicate assets. In the case of Cameroon where the telephone companies are national concessions, the sharing of critical infrastructure is a useful way to enhance network capacity utilization. With modern technology available, the capacity for providing certain services like message transmission has gone up. Those companies that encourage usage of their infrastructure tend to have lower unit operating costs.

In Cameroon, some concession holding firms have found different innovative ways of encouraging the use of extra capacity in their networks. Call bonuses and discounts are 
provided to consumers during low pick hours like nights and Sunday mornings, and are specifically designed to discriminate in favour of low end users. Unlimited SMS, MMS and Data volumes are provided on premium charge or provided as bonus bundles when other services are purchased.

However, it is also important to consider the cost benefits of high capacity utilization against the quality concerns that automatically arise when telecom networks are used at full capacity. It is important that firms maximize the use of their installed capacity to the extent that the network is not fully saturated.

However, some important reservations have to be made to my overall results. The distribution of costs is estimated on the basis of current services and does not take the network requirements of future services into account. The cost of services demanding more bandwidth such as the triple play (Television, Telephone, internet), HD TV, Online video, online games, video conference, and video control are much more sensitive to distance than, for example, the costs of a telephone call. This is because the capacity of the access link is often underutilized.

This indicates that demand for new types of services in the future may have a substantial impact on the future cost-profile of network operators in Cameroon. New services will also affect the cost profile in another way. In some services, the basic network provision itself will only be a minor part of the service delivered. Value added network services and intelligent services both add new activities and introduce new types of costs to network operators. Some of these costs such as development costs will be usage independent fixed costs, but they will not be regular sunk costs as service delivery will not be tied to specific geographical areas.

Another important factor is the recent introduction of forth generation (4G) licenses and the award of a new mobile license, which creates new possibilities of substituting plant and network equipment. As these new networks compete with existing ones and become part of hybrid networks, Industry-wide and Firm-specific cost profiles will continue to change. 


\section{Concluding Remarks.}

As telecom firms, regulatory and supervisory authorities in Cameroon seek better ways of enhancing the variety and quality of telecom services delivered to the public, it is important to make sure that the economic interests of all parties (Operators and Consumers) are served in an optimal fashion. Understanding the cost structure of telecom firms when they diversify production is crucial to this effort, given the central importance of cost in the internal allocation of resources within a firm, and in the determination of prices for consumers and profits for operators.

This study contributes to this effort by searching for evidence of falling operating costs as telecommunication firms increase the types of products in their output mix. Falling operating costs as output is diversified (economies of scope) is the evidence of production efficiency and has some positive welfare implications for all market participants.

However, I find compelling evidence that there are cost advantages to be derived from increased capacity utilization, but cost disadvantages resulting from the diversification of services for the service categories studied, call diversity and line diversity.

This presents a genuine problem for the operators and authorities. As market penetration peaks for traditional telecom services and rapid technological growth makes more and more network capacity available to operators, they will rightfully seek out ways to maximize capacity utilization of these networks. It is the duty of the regulatory and supervisory authorities to make sure this extra capacity is utilized in ways that do not represent anticompetitive conduct. The following recommendations can greatly aid this effort.

Presently in Cameroon, concession holding telecom firms are providing a multitude of services, some of which are hardly related to telecommunication in the first place. In order to ensure that such services do not create unfair competition in already established markets, authorities should mandate telecom firms providing those services to prepare separate accounting information for activities related to those services, and withdraw the licenses for the provision of those services if service delivery is not cost efficient.

It is also important that the sector adopts a strategy of phone number portability, and that technological restrictions that limit the use of terminal equipment to specific providers should be banned, except in cases where the equipment is service specific and only one firm provides that service. This will help to ensure healthy competition in the provision of terminal equipment and safeguard the long-term welfare of the 
consumer.

In order to enhance capacity utilization and benefit from the associated cost advantages, network operators should be encouraged to rent out extra capacity on their networks to third party service providers with an existing capacity to provide additional services in a more cost effective manner.

Finally, it is in the interest of all stakeholders in the sector that policies be driven by sound research, and current attitudes towards corporate secrecy are impeding this effort. I recommend that firms be made to comply with existing regulations on the publication of data, or encouraged to cooperate with researchers.

\section{References}

Banker, R.D., Chang, H.H., Majumdar, S.K., 1998.Economies of scope in the U.S. telecommunications industry.Information Economics and Policy 10, 253-272.

Banker, R.D., Johnston, H., 1993. An empirical study of cost drivers analysis in the U.S. airlines industry.

Accounting Review, July, 576-601.

Baumol, W. J., Braunstein, Y. M., 1977. Empirical study of scale economies and production complementarity: The case of journal publication'. Journal of Political Economy85, 1037-1048. Bloch, H., Madden, G., Savage, S.J., 2001. Economies of scale and scope in Australian telecommunications.Review of Industrial Organization 18, 219227.

Charnes, A., Cooper, W.W., Sueyoshi, T., 1988. A goal programming/ constrained regression review of the Bell system breakup. Management Science 34, 1-38.

Evans, D.S., Heckman, J.J., 1984. A test for subadditivity of the cost function with an application to the Bell System. The American Economic Review 74, 615-623.

Falch, M. 1997. Cost and demand characteristics of telecom networks. In Telecom Reform: Principles, Policies and Regulatory Practices, edited by William Melody, Denmark: Den Private Ingeniprfond: Technical University of Denmark.

Fuss, M. A., Waverman, L., 2002. Econometric cost functions. inHandbook of Telecommunications Economics. Martin Cave, SumitMajumdar, and Ingo Vogelsang, eds. Amsterdam: Elsevier Publishers, 143- 177. 
International Monetary Fund, 1999.Medium-term economic and financial policy framework paper (1999/2000-2001/02). Cameroon: Enhanced structural adjustment facility. See http://www.imf.org/external/np/pfp/1999/cameroon/

International Telecommunications Union, 2000. Telecommunication regulation in Cameroon: Present situation and outlook. Forum on Telecommunication regulation in Africa. Gaborone, Botswana. 25-27 October 2000. See www.itu.int/ITUD/treg/Events/Seminars/2000/Botswana/Documents/34-e.pdf.

Leggette, J. A., 1985. Natural monopoly in the telecommunications industry: The case of local service. Unpublished Ph.D. Dissertation, University of South Carolina.

Moon, Paren, B., 2008. Seemingly unrelated regressions. Palgrave Macmillan, City. MTN Cameroon Linkedin Profile. See https://www.linkedin.com/company/mtncameroon.

Panzar, J. C., Willig, R. D., 1975. Economics of Scale and Economies of Scope in Multi-Output Production. Bell Laboratories discussion paper 33.

Panzar, J.C., Willig, R.D., 1981. Economies of scope. American Economic Review 71, 481-492.

Pulley, L.B., Humphrey, D.B., 1993.The role of fixed costs and cost complementarities in determining scope economies and the cost of narrow banking proposals. The Journal of Business 66, 437-462.

Shin, R. T., Ying, J. S., 1992.Unnatural monopolies in local telephone.RAND Journal of Economics 23. $171-183$

Waverman, L., 1989. U.S. interexchange competition. In: Crandall, R.W., Flamm, K. (Eds), Changing the Rules: Technological Change, International Competition and Regulation in Communications. The Brookings Institution, Washington, D.C.

World Bank. 1989. Cameroon - Structural Adjustment Program Project. Washington, DC: World Bank. See http://documents.worldbank.org/curated/en/1989/05/722716/cameroon-structural-adjustmentprogram-project

Zellner, A., 1962. An efficient method of estimating seemingly unrelated regression equations and tests for aggregation bias.Journal of the American Statistical Association57, 348-368. 